\title{
Relative Frequency of Oral Malignancies and Oral Precancer in the Biopsy Service of Jazan Province, 2009-2014
}

\author{
AM Idris ${ }^{1}$, NV Vani ${ }^{1}$, Sanna Saleh ${ }^{1}$, Faisal Tubaigy ${ }^{1,4}$, Fahd Alharbi $^{1,5}$, Abubkr \\ Sharwani $^{2}$, Nabil Tadrus ${ }^{3}$, Saman Warnakulasuriya ${ }^{6 *}$
}

\begin{abstract}
Background: The objective of this study was to report the types and relative frequency of oral malignancies and precancer in the Jazan region of Saudi Arabia during the period 2009-2014. Materials and Methods: Pathology reports were retrieved from the archives of Histopathology Department, King Fahd hospital in Jazan. Demographic data on tobacco habits, clinical presentation and histologic grading of oral precancer and cancer cases were transcribed from the files. Results: 303 (42.7\%) oral pre-malignant and malignant cases were found out of 714 oral biopsy lesions. A pathology diagnosis of squamous cell carcinoma $(85.1 \%)$ was most frequent, followed by premalignant lesions/epithelial dysplasia $(8.6 \%)$, verrucous carcinoma $(3.3 \%)$ and malignancy of other histological types (3\%) such as ameloblastic carcinoma, salivary gland malignancy and sarcomas. Oral squamous cell carcinoma was predominant in females with a male to female ratio of 1:1.9. Patient age ranged from 22 to 100 years with a mean of $65 \pm 13.9$. Almost $44.6 \%$ of oral cancer had occurred after 65 years of age. Only $16.3 \%$ cases were reported in patients younger than 50 years, predominantly females. The majority of female patients had the habit of using shammah with a long duration of usage for more than 45 years. Buccoalveolar mucosa $(52.3 \%)$ was the common site of involvement followed by tongue/ floor of the mouth (47.7\%) and clinically presented mostly as ulceration/swelling clinically. Moderately differentiated tumours $(53.9 \%)$ were common followed by well differentiated $(32.2 \%)$ and poorly differentiated tumours $(5.8 \%)$. The prevalence of oral verrucous carcinoma (3.3\%) was comparatively low with an equal distribution in both males and females. Both bucco-alveolar mucosa and tongue were predominantly affected. Oral precancer/epithelial dysplasia $(8.6 \%)$ was common in females with a shammah habit. Bucco-alveolar mucosa was commonly involved and clinically presented mostly as white/red patches. Most cases were mild followed by moderate and severe dysplasia. Tumours of other histological types (3\%) include 1 ameloblastic carcinoma, 3 malignant salivary gland tumours and 5 sarcomas. Conclusions: In this study, it was found that oral cancers reported in the pathology service to be a common occurrence. This study reconfirms previous reports of the high burden of oral cancer in this population This indicates that conventional preventive programs focused on oral cancer are in need of revision. In addition, further research into identifying new risk factors and molecular markers for oral cancer are needed for screening high risk individuals.
\end{abstract}

Keywords: Shammah - oral precancer - oral malignancy - smokeless tobacco - Jazan - Saudi Arabia

Asian Pac J Cancer Prev, 17 (2), 519-525

\section{Introduction}

Oral cancer is a serious debilitating disease of the oral cavity that remains as the most common cancer in Jazan, Saudi Arabia over the years (Stirling et al, 1979; National Cancer Registry (Saudi Arabia), 1999 - 2003; Saudi Cancer Registry, 2004-2010). Most of these oral malignancies are squamous cell carcinomas with malignancies of other types forming a considerable lower percentage (Van der Waal et al, 2007). There is a worldwide geographical variation in the prevalence of oral cancer due to varied socio-cultural characteristics, differences in data collection and the level of development of health services. This could also reflect the geographic and ethnic differences in various risk factors (Warnakulasuriya, 2009). Several studies have reported high frequency of oral cancer in the south western region of Saudi Arabia, particularly Jazan province, relating to the practice of shammah use (Stirling et al., 1979; Stirling et al, 1981; Yousef et al, 1983; Amer et al, 1985; El- Akkad et al, 1986; Salem, 1992).

Review of Saudi Arabia Cancer Registry from 1999 to 2010 showed that the frequency of oral cancer is consistently high in Jazan Province. While the neighbouring regions like Asir and Najran province

${ }^{1}$ College of Dentistry, ${ }^{4}$ Ophthalmology, ${ }^{5}$ Otorhinolaryngology-Head and Neck Surgery, Faculty of Medicine, Jazan University; ${ }^{2}$ Oral Surgery, ${ }^{3}$ Histopathology Laboratory, King Fahad Hospital, Jazan, Saudi Arabia, ${ }^{6}$ King's College, London University, UK *For correspondence: amidris53@gmail.com 
reported considerably lower rates (National Cancer Registry (Saudi Arabia), 1999 - 2003; Saudi Cancer Registry, 2004-2010). Hospital statistics of GCC countries which share cultural and geographic similarities show that the prevalence of oral cancer is highest in Saudi Arabia compared to other GCC countries like UAE, Oman, Bahrain, Qatar and Kuwait (Cancer Registry GCC (1998 - 2009), 2013).

Oral epithelial dysplasia is a term assigned to the histopathological changes associated with an increased risk of malignant transformation (WHO, 2005). Presence of epithelial dysplasia is generally accepted as one of the most important predictors of malignant development in lesions but not all premalignant lesions turn into malignancy. The histopathological features of oral epithelial dysplasia are characterized by cytological atypia and architectural disturbance with loss of normal maturation and stratification of keratinocytes (Warnakulasuriya et al 2008). Conventionally, it is divided into grades: mild, moderate and severe. Accurate diagnosis of these pathologies following appropriate interventions may prevent their transformation into squamous cell carcinoma. If transformation was to take place follow up of these cases may allow early detection of cancer thereby consequently implying a better prognosis.

Retrospective studies to assess the prevalence and pattern of oral premalignant and malignant lesions are of great significance to estimate the burden of this disease in the population. Most of the studies reported only the prevalence of oral squamous cell carcinoma (Iamaroon et al, 2004; Al-Rawi et al, 2008; Effiom et al, 2008; Moracchio et al, 2010; Falaki et al, 2011; Halboub et al, 2012). But only few studies have analyzed both the prevalence of oral precancer and malignancy including non-squamous malignant tumors (Rossi et al, 1977; Salem et al, 1984; Mani, 1985; Mehrotra et al, 2008; Warnakulasuriya, 2009). Therefore the objective of this study is to retrospectively analyze the prevalence and pattern of oral premalignancy and all types of oral malignancies in Jazan region during the period 2009-2014.

\section{Materials and Methods}

King Fahd Hospital is the tertiary referral centre in Jazan Province that caters to the health needs of Jazan population. Jazan is the second smallest region in Saudi Arabia along the southern red sea coast with approximately $11,671 \mathrm{sq} . \mathrm{km}$ land area and a population of about 1.35 million. All cases with suspected oral malignant or premalignant lesions are referred to this hospital. Cases are diagnosed at the oral surgery clinic and biopsies are reported at the histopathology department. Following a manual search of the pathology data base, histologically diagnosed cases of oral premalignant and malignant lesions were retrieved from the files of histopathology department over a period of 6 years from 2009 to 2014 . These cases were analyzed for age, sex, tobacco habits, anatomic distribution of the lesion, clinical appearance, histologic type and histologic grading in case of squamous cell carcinoma and epithelial dysplasia. Repeat biopsies or biopsies of recurrent cases were grouped as a single case. The haematoxylin and eosin stained tissue sections of these tumours including their histological grading were re-evaluated by three experienced oral pathologists with the consultation of a histopathologist using quadrifocal microscope. Consensus was reached in doubtful cases. The data was entered into an excel database and statistical analysis was carried out by SPSS (IBM, version 20). At first, data management was performed by running frequencies, whenever there are extreme values or an outlier, the data is rechecked and the value is corrected or removed. Then descriptive statistics was performed to check the level of variability at a confidence interval of $95 \%$ by applying chi square test of significance.

\section{Results}

During this 6 year period (2009 - 2014), 714 (2.2\%) oral biopsies were accessioned by the hospital. Among them, $303(42.6 \%)$ were oral pre-malignant and malignant lesions. Squamous cell carcinoma (258) was the most frequent histologic type accounting for $85.1 \%$, followed with premalignant lesions / epithelial dysplasia $26(8.6 \%)$, verrucous carcinoma 10 (3.3\%) and malignancies of other histological types $9(3 \%)$ which include ameloblastic carcinoma, salivary gland malignancy and sarcomas

Table 1. Prevalence of Oral Malignant Neoplasm and Precancer among 714 Oral Biopsies (2009 to 2014)

\begin{tabular}{|c|c|c|}
\hline Number of cases & Males & Females \\
\hline \multicolumn{3}{|l|}{ Squamous cell carcinoma } \\
\hline $258(36.1 \%)$ & $90(34.9 \%)$ & $168(65.1 \%)$ \\
\hline \multicolumn{3}{|l|}{ Verrucous carcinoma } \\
\hline $10(1.4 \%)$ & $5(50 \%)$ & $5(50 \%)$ \\
\hline \multicolumn{3}{|c|}{ Oral precancer/Epithelial dysplasia } \\
\hline $26(3.6 \%)$ & $12(46.2 \%)$ & $14(53.8 \%)$ \\
\hline \multicolumn{3}{|l|}{ Other malignant tumors } \\
\hline $9(1.2 \%)$ & $4(44.5 \%)$ & $5(55.5 \%)$ \\
\hline \multicolumn{3}{|l|}{ Ameloblastic carcinoma } \\
\hline $1(11.1 \%)$ & -- & $1(100 \%)$ \\
\hline \multicolumn{3}{|l|}{ Salivary gland malignancy } \\
\hline $3(33.3 \%)$ & $2(66.7 \%)$ & $1(33.3 \%)$ \\
\hline \multicolumn{3}{|l|}{ Sarcomas } \\
\hline $5(55.6 \%)$ & $2(40 \%)$ & $3(60 \%)$ \\
\hline \multicolumn{3}{|l|}{ Total } \\
\hline $303(42.4 \%)$ & $111(36.6 \%)$ & $192(63.4 \%)$ \\
\hline
\end{tabular}

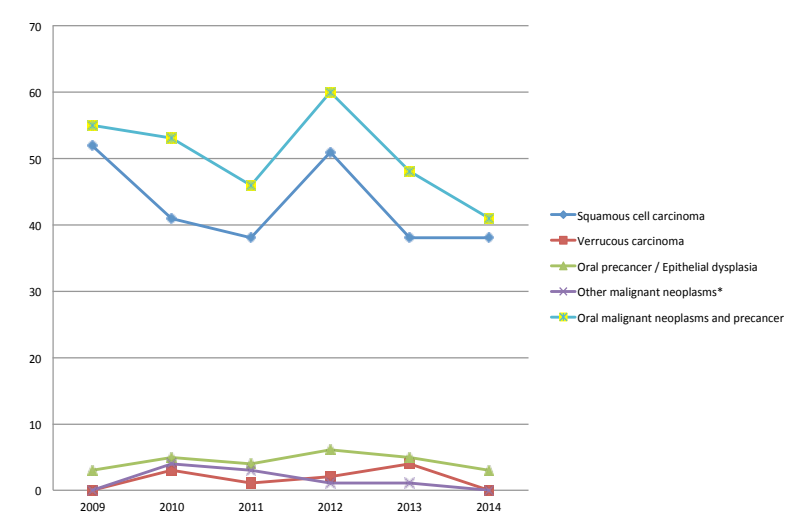

Figure 1. Distribution of Oral Malignant Neoplasm and Precancer Over the Years (2009 to 2014). *Odontogenic and Salivary Tumors and Sarcoma 
(Table 1). These contributed to approximately $14.7 \%$ of the total body malignancies. Moreover, analysis of the data over the years showed that the incidence of oral cancer decreases from 2009 to 2011 followed by a sharp increase with a point of inflexion in 2012 after which there is a decline again (Figure 1).

Oral squamous cell carcinoma was common in females $(65.1 \%)$ compared to males $(34.9 \%)$ with a male to female ratio of 1:1.9 (Table 1). Patient's age ranged from 22 to 100 years with a mean of $65 \pm 13.9$. Almost $44.6 \%$ of these cases have occurred after 65 years of age with only $16.3 \%$ in patients younger than 50 years. In relation to tobacco habits, majority of the females patients were shammah users and they also showed higher duration of use for more than 45 years. Bucco-alveolar mucosa $(52.3 \%)$ was the frequently involved site followed by tongue/ floor of the mouth $(47.7 \%)$. Most of these tumours $(81.4 \%)$ had presented clinically as an ulcer or a swelling (Table 2). Females showed the highest percentage of moderately and well differentiated tumours, however poorly differentiated tumours were common in males (Table 3). Analysis of the histological grades of these tumours in relation to shammah habit showed that poorly differentiated tumours were common in shammah users and moderate to well differentiated tumours were relatively common in non-shammah users (Table 3 ). While the data on shammah habits reported by users is reliable, data from non-users is doubtful as unless patients are questioned on use of shammah in the clinic, they will not convey the information.

Verrucous carcinoma, a variant of squamous cell carcinoma formed only $3.3 \%$ of oral cancers. This relative frequency is low in view of shammah usage in this region, probably because distinction between verrucous carcinoma and squamous cell carcinoma is subjective and most of the verrucous carcinoma cases at later stage may change to invasive carcinoma. Males and females were equally affected. Tongue / floor of the mouth were commonly affected in females, while bucco-alveolar mucosa was the common site of occurrence in males (Table 2).

Oral precancer / epithelial dysplasia occurred more commonly in males older than 65 years, the age distribution for females was similar in all age groups. Females were found to have more shammah usage. The distribution according to site, showed that bucco-alveolar mucosa is commonly involved in males; tongue and bucco - alveolar mucosa in females. The predominant clinical presentation was a white-red patch for females while it was associated with an ulcer for males and found to be statistically significant $(p=0.007)$ (Table 2 ). Both mild and severe dysplasia was distributed equally in both males and females while moderate dysplasia was common in males (Table 3). Tumours of other histological types were very few accounting for only $3 \%$ of the total oral malignancy. This includes 1 case of ameloblastic carcinoma, 3 cases of malignant salivary gland tumours and 5 cases of sarcomas (Table 1). The low occurrence of these tumours is difficult to explain, probably because most of the odontogenic and salivary gland tumours are reported benign.

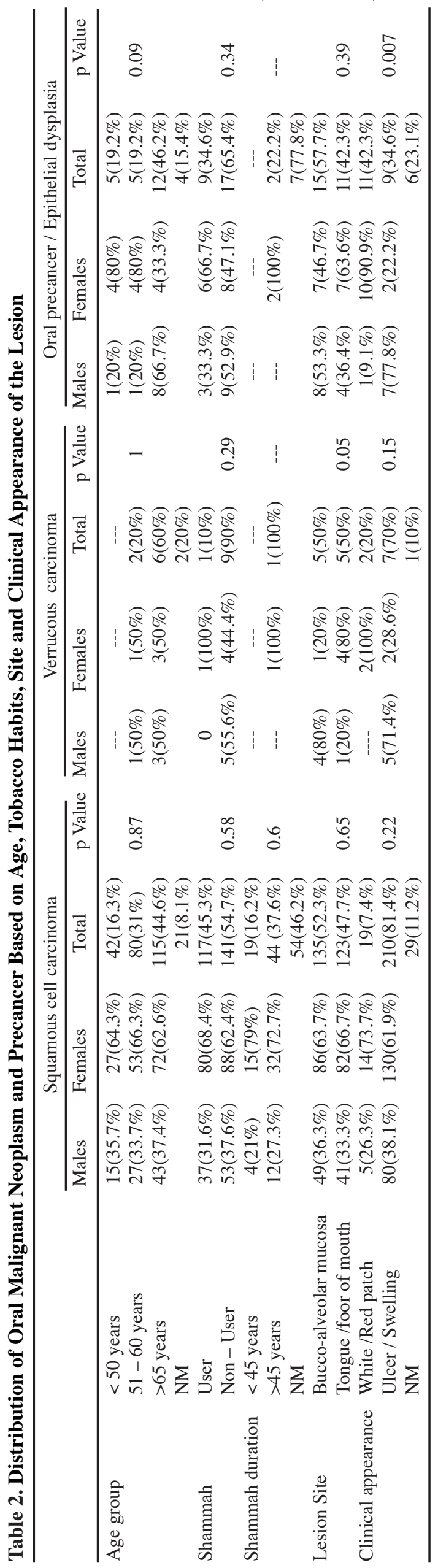

Asian Pacific Journal of Cancer Prevention, Vol 17, 2016 


\begin{tabular}{|c|c|c|c|c|c|c|c|c|c|c|c|}
\hline & & \multicolumn{5}{|c|}{ Squamous cell carcinoma } & \multicolumn{5}{|c|}{ Oral precancer / Epithelial dysplasia } \\
\hline & & Grade 1 & Grade II & Grade III I & No grading & $\mathrm{p}$ Value & Mild & Moderate & Severe & No grading $\mathrm{p}$ & $\mathrm{p}$ value \\
\hline \multirow[t]{2}{*}{ Sex } & Males & $28(33.7 \%)$ & $46(33.1 \%)$ & $9(60 \%)$ & $7(33.3 \%)$ & 0.21 & $6(50 \%)$ & $2(33.3 \%)$ & $3(50 \%)$ & $1(50 \%)$ & 0.91 \\
\hline & Females & $55(66.3 \%)$ & $93(66.9 \%)$ & $6(40 \%)$ & $14(66.7 \%)$ & & $6(50 \%)$ & $4(66.7 \%)$ & $3(50 \%)$ & $1(50 \%)$ & \\
\hline \multirow[t]{2}{*}{ Shammah } & User & $36(43.4 \%)$ & $64(46 \%)$ & $9(60 \%)$ & $8(38.1 \%)$ & 0.69 & $4(33.3 \%)$ & $3(50 \%)$ & $2(33.3 \%)$ & --- & 0.63 \\
\hline & Non-user & $47(56.6 \%)$ & $75(54 \%)$ & $6(40 \%)$ & $13(61.9 \%)$ & & $8(66.7 \%)$ & $3(50 \%)$ & $4(66.7 \%)$ & $2(100 \%)$ & \\
\hline Total & & $83(32.2 \%)$ & $139(53.9 \%)$ & $15(5.8 \%)$ & $21(8.1 \%)$ & & $12(46.1 \%)$ & $6(23.1 \%)$ & $6(23.1 \%)$ & $2(7.7 \%)$ & \\
\hline
\end{tabular}

\section{Discussion}

The incidence of oral cancer varies from one country to another, which can be explained by the difference in the distribution of risk factors and possible aetiologies. The high prevalence rate of oral precancer and cancer is reported in South East Asian countries such as Sri Lanka, India, Pakistan and Bangladesh. Oral cancer is the most common cancer contributing up to $25 \%$ of all new cases of cancer in these high risk countries (Warnakulasuriya, 2009). According to Globacan 2002 data, Sri Lanka has the highest incidence of oral cancer in the South Asia. It is the most common cancer in males with $15.5 \%$ of all cancers reported in the mouth (Ferlay et al, 2004). The relative frequency of oral cancer compared to other cancers was $14.7 \%$ in the present study and is close to the figures of Srilanka. However, this is relatively higher compared to $10 \%$ reported in Portugal (Dias et al, 2007) and 3.5\% in Thailand (Vatanasapt et al, 1993). Oral cancers formed $42.4 \%$ of cases among oral biopsied service in this study that is quite high compared to $10.8 \%$ in Nigeria (Effiom et al, 2008) and $14.7 \%$ in UAE (Anis et al, 2013). However, this figure may be influenced by the clinical decisions whether to biopsy or not a soft tissue oral lesion noted in the oral cavity.

Hospital statistics from Saudi Arabia have shown that oral cancer constituted $4.3-17.8 \%$ of all registered cancers (Koreich et al, 1984; Amer et al, 1985; El-Akkad et al, 1986). A 20 year review on oral cancer among Saudi cancer patients referred to King Faisal Specialist Hospital and Research Center has identified that 35.4\% of oral cancer in Jazan province were related to habitual intraoral placement of a smokeless tobacco product (shammah). These data suggest there is a relationship between shammah and oral cancer in Jazan province (Allard et al, 1999).

The present study shows that the oral cancer incidence decreases from 2009 to 2011 followed by a sharp increase in 2012 after which there is a decline again. This is similar to the data in USA which has shown a decline in oral and pharyngeal cancer for the period 1995 - 2004 (SEER, 2008). Even in Sri lanka, where the incidence of oral cancer was always high (Ariyawardana et al, 2011) reported a declining trend in the recent years. Contrary to our findings, the oral cancer incidence in Saudi Arabia shows an upward trend in the recent years (National Cancer Registry (Saudi Arabia), 1999 - 2003; Saudi cancer registry, 2004-2010). In UK, an average increase of $2.7 \%$ each year has been reported (CRUK, 2012), and this is attributed in earlier reports due to an increased consumption of alcohol (Hindle et al, 2000).

Another notable finding is that the relative frequency of oral squamous cell carcinoma (85.1\%) is relatively higher in Jazan region compared to the extremely low relative frequency of oral malignant tumours of other histological types. This is in consistent with the demographic report in Jordan (84\%) (Rawashdeh et al, 2004). A lower proportion was reported in a study conducted in UAE (77\%) (Anis et al, 2013), Libya (41\%) (Subhashraj et al, 2009). Conversely, OSCC constituted a higher proportion of oral malignancies in Malaysia (91.3\%) (Khan et al, 2008), Pakistan (92.2\%) (Akram et al, 2010).

The preponderance of female cases over males in this study is in disagreement with other reports. Oral cancer is more common in men than in women in most countries (Dias et al, 2007; Al-Rawi et al, 2008; Effiom et al 2008; Halboub et al, 2012; Anis et al, 2013). Even few studies within Saudi Arabia reported male predominance (Al- Idrissi, 1990; Al-Ghamdi et al, 1994; Allard et al, 1999). The male predominance in these studies is mainly attributable to heavier indulgence in risk habits by men and exposure to sunlight as part of outdoor occupations. However, literature cites that the ratio of male to female diagnosed with oral cancer has declined over the decades worldwide and is now about 1.5:1. On the other hand, the male to female ratio in this study is $1: 1.7$ and this is undoubtedly due to more indulgence by women in their chronic usage of shammah dipping. Few early studies also reported female predominance in Jazan Province related to Shammah associated oral cancer (El-Akkad et al, 1986; Allard et al, 1999; Brown et al, 2006). Age standardized incidence report of the Saudi Arabia Cancer Registry from 1998-2009 showed that in Jazan, Asser and Najran province, tongue cancer is high in women compared to men (National Cancer Registry (Saudi Arabia), 1999 2003; Saudi Cancer Registry, 2004-2010).

The risk of developing OSCC increases with age and the majority of cases are reported in patients over 65 years. Only $16.3 \%$ of OSCC patients were younger than 50 years. The diagnosis of oral cancer at a younger age indicates the need to biopsy suspicious oral lesions to rule out malignancy in high risk patients as young as in their second or third decade. The most frequent anatomic location was bucco- alveolar mucosa followed by tongue / floor of the mouth. The high incidence of OSCC in this site is due to dipping of shammah in the buccal vestibule which is prevalent in this region. Likewise, buccal cancer is more common among Asian populations due to betel quid / tobacco chewing habits. In Sri Lanka, oral cancers were found to be predominant in buccal mucosa 
(Warnakulasuriya, 2009). But the most frequently affected sites for oral cancer in Western countries are the ventrolateral aspects of the tongue and the floor of the mouth, accounting for more than $50 \%$ of the cases (Boyle et al, 1990). Our finding is further consistent with several earlier reports from Jazan region citing buccal mucosa as the frequent site for oral cancer in shammah users (Yousef et al, 1983; Amer et al, 1985). The high risk involving these sites is explained by the fact that constant dipping of shammah allows the carcinogens to be mixed with saliva which can easily penetrate the mucosa.

Our study reveals that $45.3 \%$ of oral cancer patients were shammah users, which was more prevalent among women. However, this figure is comparatively higher than $26.2 \%$ reported earlier (Al Idrissi et al, 1990). Another study conducted in Saudi Arabia reported that all oral cancer cases were associated with shammah and qat (Ibrahim et al, 1986). Earlier, it was reported that in Jazan Province, $35.4 \%$ of oral cancer cases were associated with shammah (Allard et al, 1999). The composition of various types and brands of shammah shows variation in the types of tobacco leaves used and also the color and odor. There is variation from one user to the next and from one region and country to the other (Stirling et al, 1981; Amer et al, 1985). There are some 4500 villages in Jazan province, suggesting even further likelihood of variation. Another study from this region showed that all patients who had the 'shammah' habit developed leukoplakia in the area where it was habitually kept (Mani, 1985). In one report, $89 \%$ of the patients with oral cancer gave a history of shammah usage (Stirling et al, 1981) while in other study, only $49 \%$ of oral cancer patients admitted to using shammah (Amer et al, 1985). As shammah is illegal in this country (Masironi et al, 1992), there may be some reluctance to admit their use and therefore, actual reported percentages may be even lower. In a study conducted by Salem (1984) in Jazan province reported that oral leukoplakia has been found to affect approximately $68 \%$ of Shammah users (Salem, 1984). Another study by the same author on the prevalence of leukoplakia in relation to tobacco habits $(\mathrm{n}=1,436)$ in Jazan Region reported a prevalence of $11.4 \%$, out of which $99 \%$ were Shammah users (Salem, 1992). All these findings point to a possible causal relationship between the use of 'Shammah' and the development of oral premalignant and malignant lesions among snuff-dippers in the Jazan region.

Previous study by Al- Idrissi et al showed that poorly differentiated OSCC are more common followed by moderate and well differentiated tumours (Al- Idrissi et al, 1990). But some studies showed that well differentiated tumours were predominant followed by moderately and poorly differentiated tumours (Al-Rawi et al, 2008; Halboub et al, 2012; Anis et al, 2013). A study on Nigerian population showed that poorly differentiated tumors are most common followed by well and moderately differentiated tumours (Effiom et al, 2008). Conversely, our study found moderately differentiated tumours to be most common followed by well and poorly differentiated tumours, similar to a study in Pakistan (Bhurgri et al, 2006).

Oral epithelial dysplasia (OED), the precancerous lesion was found to be $3.6 \%$ in our study. This seems to be higher than the rate reported in earlier studies (Lumerman et al, 1995; Pereira et al, 2011). There was a slight female predominance with a male to female ratio of 1: 1.16 , in congruence with Pereira et al. This is perhaps due to increase in the usage of shammah among women. $34.6 \%$ of cases were shammah users and the remaining $65.4 \%$ have not given a history of shammah usage. Bucco - alveolar mucosa was the most frequently involved site followed by tongue and floor of the mouth, in consistent with other studies (Pereira et al, 2011). However, few studies have reported that the tongue and floor of the mouth were the most common sites for OED (Katz et al, 1985; Lumerman et al, 1995). Mild dysplasia was common followed by moderate and severe dysplasia as found by Pereira et al.

Oral malignancy worldwide consists of $90 \%$ primary squamous cell carcinoma. The remaining $10 \%$ malignant tumour of non-squamous type consisting of a heterogeneous group of tumours of unknown causes. They consist of melanomas, intra-oral salivary gland tumours, sarcomas, malignant jaw bone tumours and malignant odontogenic tumours. In our study, the malignant tumours of other histological types was only $3 \%$ of all oral malignancies. This is considerably low compared to $32.9 \%$ reported in Sudan (Idris et al, 1995). Van der Waal et al (2007) reported case series of oral non-squamous malignant tumours, and described these tumours to have rare prevalence of 1:1,000,000 population (Van der Waal et al, 2007).

Oral cancer prevails as a significant problem in the Arab population of Jazan. Studies have reported an alarming lack of awareness about oral cancer and these gaps in knowledge need to be addressed by further public education, possibly targeted at high-risk groups. A recent study showed that the knowledge of oral cancer among the youth of Jazan, was low, thereby proposing the need for oral cancer education programs and facilities for early screening in the cancer prone region of Saudi Arabia. An interventional program effectively increased the knowledge and awareness among the youth about oral cancer per se and its prevention measures (Qadri et al, 2014).

Geographic or regional variations in the prevalence of oral cancer indicate that the socio-cultural lifestyles of a population play an important role in oral carcinogenesis (Zain et al, 2001). In Sudan, oral snuff called toombak has been implicated as a risk factor for oral malignant neoplasia (Idris et al, 1994). Likewise, among females of Indian descent in South Africa, betel nut chewing is attributed as an important factor in the high incidence of oral squamous cell carcinoma (Hille et al, 2001). Betel nut chewing is a known carcinogen in the Indian sub continent. Other risk factors include possible genetic characteristics and oncogenic virus Human papilloma virus (type 16), has recently been associated with an increase in the risk of oral squamous cell carcinoma, after adjusting for smoking (Mork et al, 2001). Saudi population are mainly Muslims and their religion prohibits them from consuming alcoholic drinks. Thus, it seems reasonable to assume that the role of alcohol in oral carcinogenesis in these people 


\section{AM Idris et al}

is negligible. However, smoking is socially acceptable. The chewing of tobacco-containing substances such as shammah and non-tobacco leaves such as qat is prevalent mainly in the Southern region of this country, particularly in the Jazan province which may contribute to the high frequency of oral cancer.

With the knowledge of risk factors, primary prevention through the elimination of tobacco consumption and chemoprevention is urgently needed. Research on the natural history of the disease, particularly which precancers will progress over time, would help to develop screening programmes tailored more to the individuals . Development of tumour markers with high sensitivity and specificity could assist the detection of patients and lesions at risk. In this study, we found that oral cancer appears to be a public health problem in this population similar to the findings in USA (Silverman S Jr, 2001). This reflects that conventional preventive programs of oral cancer are in need of revision. In addition, more input into identifying new risk factors and molecular markers for oral cancer are needed for screening individuals at risk.

\section{Acknowledgements}

Substance Abuse Research Center at Jazan University Grant No. 2014 is highly appreciated for funding this research.

\section{References}

Akram S, Mirza T, Ansari T, Mirza MA, Zaheer M (2010). Histopathological spectrum of oral lesions at DDRRL - a university based experience. Pak J Otolaryngol, 26, 17-9.

Al-Ghamdi SA, Malatani T, Kameswaran M, Khurana P(1994). Head and neck cancer in a referral center in Asir region. Ann Saudi Med, 14, 383-6.

Al-Idrissi HY (1990). Head and neck cancer in Saudi Arabia: retrospective analysis of 65 patients. J Int Med Res, 18, 515-9.

Allard WF, DeVol EB, Te OB (1999). Smokeless tobacco (shamma) and oral cancer in Saudi Arabia. Community Dent Oral Epidemiol, 27, 398-405.

Al-Rawi HN, Talabani GN (2008). Squamous cell carcinoma of the oral cavity: a case series analysis of clinical presentation and histological grading of 1,425 cases from Iraq. Clin Oral Invest, 12, 15-8.

Amer M, Bull CA, Daouk MN, et al (1985). Shamma usage and oral cancer in Saudi Arabia. Ann Saudi Med, 5, 135-40.

Anis R, Gaballah K (2013). Oral cancer in the UAE: a multicenter, retrospective study. Libyan J Med, 8, 21782.

Ariyawardana A, Warnakulasuriya S (2011). Declining oral cancer rates in Sri Lanka: are we winning the war after being at the top of the cancer league table? Oral Dis, 17, 636-41.

Bhurgri Y, Bhurgri A, Usman A, et al (2006). Epidemiological review of head and neck cancers in Karachi. Asian Pac J Cancer Prev, 7, 195-200.

Boyle P, MacFarlane J, Maisonneuve P, et al (1990). Epidemiology of mouth cancer in 1989: a review. J R Soc Med, 83, 724-30.

Brown A, Ravichandran K, Warnakulasuriya S (2006). The unequal burden related to the risk of oral cancer in the different regions of the Kingdom of Saudi Arabia. Community Dent Health, 23, 101-106.

Cancer incidence among nationals of the GCC states 1998 - 2009 (2013). Gulf centre for cancer control and prevention. CRUK http://www.cancerresearchuk.org/health-professional/ cancer-statistics. accessed 15/06/2015

Dias GS, Almeida AP (2007). A histological and clinical study on oral cancer: descriptive analyses of 365 cases. Med Oral Patol Oral Cir Bucal, 12, 474-8.

Effiom OA, Adevemo WL, Omitola OG, et al (2008). Oral squamous cell carcinoma: a clinicopathologic review of 233 cases in Lagos, Nigeria.J Oral Maxillofac Surg, 66, 1595-9.

El-Akkad SM, Amer MH, Lin GS, Sabbah RS, Godwin JT (1986). Pattern of cancer in saudi arabs referred to king faisal specialist hospital. Cancer, 58, 1172-8.

Falaki F, Dalirsani Z, Pakfetrat A, et al (2011). Clinical and histopathological analysis of oral squamous cell carcinoma of young patients in Mashhad, Iran: a retrospective study and review of literatures. Med Oral Patol Oral Cir Bucal, 16, 473-7.

Ferlay J, Pisani P, Parkin DM. GLOBOCAN 2002 (2004). Cancer incidence, mortality and prevalence worldwide. IARC Cancer Base (2002 estimates). Lyon: IARC Press.

Halboub E, Al-Mohaya M, Abdulhuq M,Al-Mandili A,Al-Anazi Y (2012). Oral squamous cell carcinoma among Yemenis: onset in young age and presentation at advanced stage. $J$ Clin Exp Dent, 4, 221-5.

Hille J, Shear M (2001). Epidemiology of oral cancer in South Africa 1988 -1995. Oral Oncol, 17, 7-12.

Hindle I, Downer MC, Moles DR, Speight PM (2000). Is alcohol responsible for more oral cancer? Oral Oncol, 36, 328-33.

Hsue SS, Wang WC, Chen CH, et al (2007). Malignant transformation in 1458 patients with potentially malignant oral mucosal disorders: a follow-up study based in a Taiwanese hospital. J Oral Pathol Med, 36, 25-9.

Iamaroon A, Pattanaporn K, Pongsiriwet S, et al (2004). Analysis of 587 cases of oral squamous cell carcinoma in northern Thailand with a focus on young people. Int J Oral Maxillofac Surg, 33, 84-8.

Ibrahim EM, Satti MB, Al Idrissi HY, et al (1986). Oral cancer in Saudi Arabia: the role of alqat and alshammah. Cancer Detect Prev, 9, 215-8.

Idris AM, Prokopczyk B, Hoffmann D (1994). Toombak: a major risk factor for cancer of the oral cavity in Sudan. Prev Med, 23, 832-9.

Idris AM, Ahmed HM, Mukthar BI, Gander AF, El-Beshir EI (1995). Descriptive epidemiology of oral neoplasms in Sudan 1970-1985 and the role of toombak. Int J Cancer, 61, 155-8.

Katz HC, Shear M, Altini M (1985). A critical evaluation of epithelial dysplasia in oral mucosal lesions using the SmithPindborg method of standardisation. J Oral Pathol Med, 14, 476-82.

Khan AR, Anwar N, Manan AHB, Narayan KA (2008). Case series analysis of oral cancer and their risk factors. Malays Dent J, 29, 46-50.

Koreich OM, Alkuhaymi R (1984). Cancer in Saudi Arabia: Riyadh Al-Kharji Hospital Programme experience. Saudi Med J, 5, 217-224.

Lumerman H, Freedman P, Kerpel S (1995). Oral epithelial dysplasia and the development of invasive squamous cell carcinoma. Oral Surg Oral Med Oral Pathol Oral Radiol Endod, 79, 321-9.

Mani NJ (1985). Preliminary report on prevalence of oral cancer and precancerous lesions among dental patients in Saudi Arabia. Community Dent Oral Epidemiol, 13, 247-8.

Masironi R (1993). WHO strategies to curb smokeless tobacco: a global perspective. In: Shopland DR, Stotts RC, Schroeder KL, Burns DM, editors. Smoking and tobacco control. Monograph 2, Smokeless tobacco or health: an international perspective. NIH publication no. 93-3461. U.S. 
Department of Health and Human Services; Public Health Service; National Institutes of Health. Bethesda, Maryland. September 1992. Reprinted May 1993:315-22.

Mehrotra R, Pandya S, Chaudhary AK, Kumar M, Singh M (2008). Prevalence of oral pre-malignant and malignant lesions at a tertiary level hospital in Allahabad, India. Asian Pac J Cancer Prev, 9, 263-5.

Moracchio LS, Lima J, Sperandio FF, Correa L, De Sousa SOM (2010). Oral squamous cell carcinoma: an analysis of 1,564 cases showing advances in early detection. J Oral Sci, 52, 267-73.

Mork J, Kathrine L, Glattre E, et al (2001). Human papilloma virus as a risk factor for oral squamous cell carcinoma: a metaanalysis, 1982-1997. New Engl J Med, 344, 1125-31.

National Cancer Registry (Saudi Arabia) (2004). Saudi Arabia Cancer Incidence Report 1999-2000. Riyadh, Saudi Arabia: National Cancer Registry (Saudi Arabia).

National Cancer Registry (Saudi Arabia) (2005). Saudi Arabia Cancer Incidence Report 2001. Riyadh, Saudi Arabia: National Cancer Registry (Saudi Arabia).

National Cancer Registry (Saudi Arabia). Saudi Arabia Cancer Incidence Report 2002. Riyadh, Saudi Arabia: National Cancer Registry (Saudi Arabia).

National Cancer Registry (Saudi Arabia). Saudi Arabia Cancer Incidence Report 2003. Riyadh, Saudi Arabia: National Cancer Registry (Saudi Arabia).

Pereira JS, Carvalho MV, Henriques ACG, et al (2011). Epidemiology and correlation of the clinicopathological features in oral epithelial dysplasia: analysis of 173 cases. Ann diag pathol, 15, 98-102.

Quadri MFA, Saleh SM, Alsanosy R, et al (2014). Effectiveness of an intervention program on knowledge of oral cancer among the youth of jazan, Saudi Arabia. Asian Pac J Cancer Prev, 15, 1913-8.

Rawashdeh MA, Matalka I (2004). Malignant oral tumors in Jordanians, 1991- 2001. A descriptive epidemiological study. Int J Oral Maxillofac Surg, 33, 183-8.

Rossi EP, Hirsch SA (1977). A survey of 4,793 oral lesions with emphasis on neoplasia and premalignancy. J Am Dent Assoc, 94, 883-6.

Salem G, Juhl R, Schiodt T (1984). Oral malignant and premalignant changes in 'Shammah-users from the Gizan region, Saudi Arabia. Acta Odontol Scand, 42, 41-45.

Salem G (1992). Leukoplakia and tobacco habits in Gizan, Saudi Arabia. Saudi Dent J, 4, 50-4.

Saudi Cancer Registry. Saudi Arabia Cancer Incidence Report 2004. Riyadh, Saudi Arabia: Saudi Cancer Registry (Saudi Arabia).

Saudi Cancer Registry. Saudi Arabia Cancer Incidence Report 2005. Riyadh, Saudi Arabia: Saudi Cancer Registry (Saudi Arabia).

Saudi Cancer Registry. Saudi Arabia Cancer Incidence Report 2006. Riyadh, Saudi Arabia: Saudi Cancer Registry (Saudi Arabia).

Saudi Cancer Registry. Saudi Arabia Cancer Incidence and Survival Report 2007. Riyadh, Saudi Arabia: Saudi Cancer Registry (Saudi Arabia).

Saudi Cancer Registry. Cancer Incidence Report in Saudi Arabia 2008. Saudi Oncology Society.

Saudi Cancer Registry. Cancer incidence report. Saudi Arabia 2009. Riyadh, Saudi Arabia: Saudi Cancer Registry (Saudi Arabia).

Saudi Cancer Registry. Cancer incidence report. Saudi Arabia 2010. Riyadh, Saudi Arabia: Saudi Cancer Registry (Saudi Arabia).

Silverman S Jr (2001). Demographics and occurrence of oral and pharyngeal cancers. The outcomes, the trends, the challenge.
$J$ Am Dent Assoc, 132, 7-11.

Stirling G, Khalil A, Nada G, Saad A and Raheem M (1979). Malignant neoplasms in Saudi Arabia. Cancer, 45, 1543.

Stirling G, Zahran F, Jamjoom A, Eed D (1981). Cancer of the mouth in the western region of Saudi Arabia. A Histopathological and Experimental Study. King Abdulaziz. Med J, 1, 10-6.

Subashraj K, Orafi M, Nair KV, El-Gehani R, Elarbi M (2009). Primary malignant tumors of orofacial region at Benghazi, Libya: a 17 years review. Cancer Epidemiol, 33, 332-6.

Surveillance epidemiology and end results (SEER). SEER Cancer statistics review 1975-2004. National Cancer Institute. Available from: http://seer.cancer.gov/ statfacts/ html/oralcav (accessed 03.03.08).

Van der Waal R, Van der Waal I (2007). Oral non-squamous malignant tumors; diagnosis and treatment. Med Oral Patol Oral Cir Bucal, 12, 486-91.

Vatanasapt V, Martin N, Sriplung H, et al (1993). Cancer in Thailand 1988-1991. IARC Technical Report No. 16, Lyon.

Warnakulasuriya S, Reibel J, Bouquot J, Dabelsteen E (2008). Oral epithelial dysplasia classification systems: predictive value, utility, weaknesses and scope for improvement. J Oral Pathol Med, 37, 127-33.

Warnakulasuriya S (2009). Global epidemiology of oral and oropharyngeal cancer. Oral Oncology, 45, 309-16.

World Health Organization of Tumours (2005). In: Barnes L, Eveson JW, Reichart P, Sidransky D, eds. Lyon: International agency for research of cancer (IARC) IARC Press. Pathology \& Genetics. Head and Neck Tumours, pp.177-179.

Yousef A, Hashash M (1983). Common features and surgical interference in a prevalent oral cancer in Saudi Arabia. $J$ Laryngol Otol, 97, 837-43.

Zain RB (2001). Cultural and dietary risk factors of oral cancer and precancer - a brief overview. Oral Oncol, 37, 205-210. 